\title{
Regional Disparities In Human Development: The Case Of Moroccan Regions
}

\author{
Nour Eddine Aguenane ${ }^{1}$ \\ Faculty of Law, Economics, and Social Sciences, Ibn Zohr University, Agadir, Morocco
}

\begin{abstract}
Purpose of the study: This study has three objectives: a) to draw up a typology of the 10 regions of Morocco according to their level of human development; b) to develop a synthetic regional indicator, and c) to measure the extent of regional disparities in terms of human development.
\end{abstract}

Keywords: Human development, Regional disparities, Standard of living, Health, Education, Moroccan regions.

Methodology: The analysis uses statistical indicators from the household panel survey conducted in 2017 by the National Human Development Observatory in Morocco. The Principal Component Analysis (conducted using the SPSS statistics V23 software) is used to draw a typology of regions according to their level of human development. It is also used to develop a regional composite indicator. As regards the measurement of the degree of regional inequalities, the Gini index is adopted.

Main Findings: The typological cartography and the composite index developed showed the coexistence of three strata of regions with three levels of human development: low, medium, and high. The calculation of a fairly strong Gini index raises the gravity of these inequalities. The main sources of inequality are an inequitable distribution of living standards and unbalanced access to basic social amenities.

Research implications: Today, in Morocco, an ad hoc committee responsible for the new development model is collecting, arranging, and structuring the recommendations of the various actors and drawing up their conclusions. The present study is a contribution that aims to place the human being at the heart of this model. The eradication of regional disparities in terms of human development, particularly in terms of standard of living and access to basic equipment is a priority.

Novelty/Originality: This paper examines regional disparities through the prism of human development. The works which have dealt with this subject at the level of Morocco have focused on income as a standard for measuring inequalities. This study does not abandon income, but it aims to be multidimensional as soon as it integrates other no less decisive dimensions on people's lives.

\section{INTRODUCTION}

On December 12, 2019, a special commission on a new development model was set up in Morocco. Adopting an inclusive and participative approach, its objective is to meet the eyes and bring out the main inflections that allow adapting the current model so that people are at the center of development. According to Amadeus (2019), this new model has a legitimate ambition for growth based on economic prosperity, the fulfillment, and development of the capacities of individuals, inclusiveness, equal opportunities, solidarity, and sustainability.

The success of this new development dynamic, placing the individual at the center of the new model is dependent on the quality of its implementation at the regional level. Today, more than ever, the territorialization of public policies is considered a strategic choice to optimize the efforts of the State in its various territories (CESE, 2016). It is in this sense that Morocco has registered its strategic decision of advanced regionalization in its new constitution of 2011 and implemented it within the framework of the organic law of 2015. The objective is to delegate more prerogatives and powers to local stakeholders and elected authorities. Thus, State-region program contracts would improve the targeting and convergence of public policies since national strategies would be perfectly consistent with the needs of each region (Amadeus, 2019).

These strategic projects should be based on an in-depth analysis of the development characteristics of each region. Each of them has advantages and constraints. Ignorance or marginalization of these points can prevent any attempt to move forward together. Thus, the collective ambition for development would quickly be eroded by the widening of already existing sociospatial inequalities (Tamsamani, Brunet-Jailly, Komat, Mourji, 2019).

This paper aims to examine regional disparities through the prism of human development. It is articulated in three main axis. First, it proposes to build a typological mapping of the 10 Moroccan regions. Then, 16 elementary indicators representing four dimensions (education, health, the standard of living, and access to basic equipment) will be aggregated to develop a regional

\footnotetext{
${ }^{1}$ Corresponding Author: noureddine.aguenane@edu.uiz.ac.ma
} 
composite human development index (RHDI). Finally, the degree of disparities between these regions will be measured, first at the level of the synthetic index and second at the level of the elementary indicators selected.

\section{METHODOLOGY}

This empirical study uses statistical data obtained entirely from the household panel survey conducted in 2017 by the National Observatory for Human Development in Morocco. It intends to examine the similarities and dissimilarities in terms of human development between the Moroccan regions. To this end, Principal Component Analysis (PCA) is used to generate homogeneous groups of regions and draw a regional mapping of human development. The PCA is also used to develop a composite index that reflects the situation in each region. With regard to the question of measuring the extent of disparities between these regions, several indicators are proposed by the literature. This analysis will adopt the Gini index.

Principal Component Analysis is one of the descriptive factorial methods. It analyzes quantitative data, difficult to interpret as such, to provide the main dimensions (Jolliffe and Cadima, 2016). It offers pictorial representations from a rectangular table of data comprising the values of $\mathrm{p}$ quantitative variables characterizing $\mathrm{n}$ individuals (Duby et al. 2006). The aim is twofold (Bonifas et al., 1984): to explore the resemblance - by calculating the distance - between individuals $\mathrm{n}$ to see if there is a structure not known a priori and to explore linear connections - by calculating correlation and covariance - across all variables p. Thus, for individuals, similar groups are distinguished from those who are not, and for the variables, those which are most correlated are distinguished from those which are not. Such a representation extracts the information contained in the initial table without losing the essential.

The Gini index is a synthetic indicator used to assess the level of inequality by providing information on the distribution of a variable. It varies between 0 and 1 . It is equal to 0 in the case of perfect equality. In our case, when all regions have the same level of human development. At the other extreme, it equals 1 in the situation of maximum inequality.

\section{ANALYSIS AND RESULTS}

\subsection{Regional human development mapping}

A first analysis was applied to 30 elementary human development indicators from the household panel survey (Observatoire National du Développement Humain, 2018). This exploratory step allowed us to sort these indicators and to define a representative and discriminating list made up of 19 indicators. To approach the disparities between the 10 regions of Morocco, we apply the Principal Component Analysis to the 19 selected indicators. These cover four main dimensions of human development (Aguenane, 2019a), namely:

- Education: This dimension is represented by the "Literacy rate of 15 to 24 year-olds", the "Net enrollment rate for 6 to 22 years old", the "Number of years of education," the "School life expectancy," the "share of the population aged 20 and over with high school level and above", the "Share of the population aged 20 and over with no level of education".

- Health: The "Rate of medical consultation represents this dimension," the "Proportion of women benefiting from prenatal consultation during pregnancy," the "Proportion of women having given birth in a supervised environment."

- Standard of living: This dimension is represented by the "Average annual expenditure per person in current DH," the "Absolute poverty rate," the "Vulnerability rate," the "Relative poverty rate," the "Rate of households classified as poor or relatively poor (perceived poverty)," the "Percentage (\%) of the population having an annual expenditure below the national average."

- Access to basic equipment: This dimension is assessed by the "Proportion of households connected to the drinking water network," the "Proportion of households connected to the sewer network," the "Proportion of households discharging wastewater into septic tanks, wells or latrines," the "Proportion of rural households with access to dispensaries or communal health centers."

The Principal Components Analysis conducted using SPSS Statistics v23 software generates the following factorial Components:

Table 1

Total variance explained

\begin{tabular}{lccccccccc}
\hline Components & F1 & F2 & F3 & F4 & F5 & F6 & F7 & F8 & F9 \\
\hline Total & 10,213 & 4,034 & 1,405 & 0,92 & 0,574 & 0,396 & 0,237 & 0,18 & 0,04 \\
\% of variance & 56,739 & 22,414 & 7,808 & 5,109 & 3,187 & 2,201 & 1,319 & 0,999 & 0,224 \\
\% cumulative & 56,739 & 79,153 & 86,961 & 92,069 & 95,257 & 97,458 & 98,777 & 99,776 & 100 \\
\hline
\end{tabular}

Source: Author's calculation

The factorial plan (F1, F2) synthesizes the information up to $79.15 \%$ of the total variance explained. The projection of the indicators retained on this factorial plane makes it possible to visualize their correlation and their contribution to the formation of the components. Generally, the most interesting points are those which are closer to the axis and further from the origin. 
These points will characterize each of the two-axis and allow us, therefore, to interpret the typological mapping of Moroccan regions according to the level of human development.

The first axis (F1) explains $56.74 \%$ of the total variance. It is strongly correlated with the most basic human development indicators (16 of the 19 indicators selected). To its left are distributed variables reflecting a high level of social development, such as "Average annual expenditure per person in current DH," the "Share of the population aged 20 and over with high school level and above", "Number of years of education," "School life expectancy, "Medical consultation rate, "the "Proportion of women who gave birth in a supervised environment," the "Proportion of households connected to the sewer system." To its right are positioned variables reflecting a low level of human development such as the "Percentage of the population with an annual expenditure below the national average," the "Share of the population aged 20 and over with no level of education (uneducated) ", THE "Relative poverty rate," and the "Vulnerability rate."

The second axis (F2) explains $22.41 \%$ of the total variance. It is strongly linked to indicators relating to access to basic social equipment such as the "Proportion of rural households with access to dispensaries or communal health centers," and the "Proportion of households connected to the drinking water network."

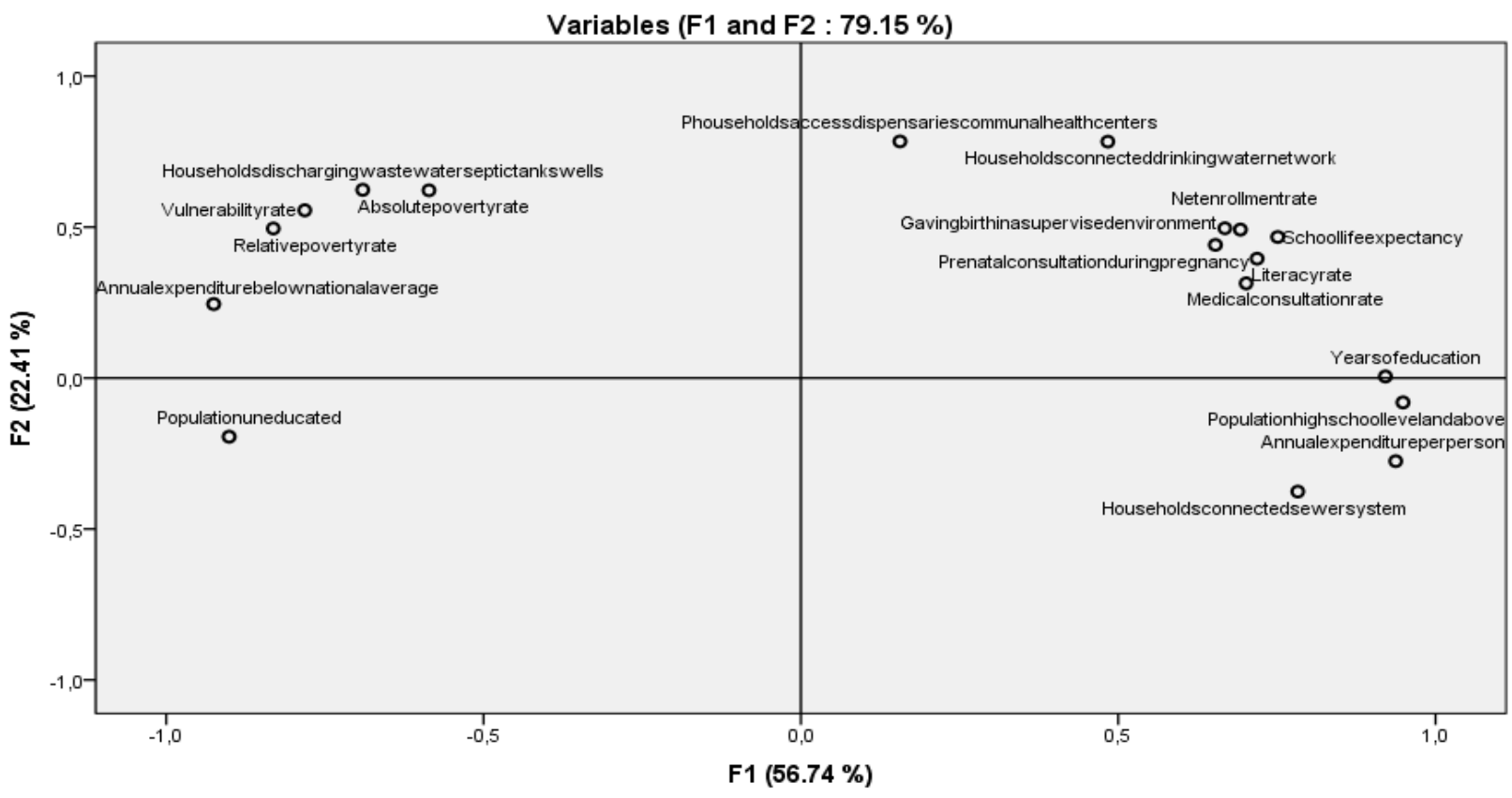

Figure 1:

Projection of the indicators on the factorial plane (F1, F2)

Source: Author's computation /SPSS (Version 23.0 for Windows) Output

Graphically, we can say that (F1) is an axis of human development. It classifies the different regions, from left to right, according to the level of education, health, and standard of living, at the moment when the second axis (F2) classifies the regions according to the level of access to basic social equipment, particularly access to drinking water and health centers. The projection of the regions on this plane makes it possible to distinguish three homogeneous groups.

The first group is made up of the Régions du Sud, Casablanca-Settat, and Rabat-Salé-Kenitra. These regions have high coordinates on the first axis, thus demonstrating a high level of human development. Only these three regions recorded, in 2015 , a human development index (HDI) higher than the national average (0.647). Indeed, Casablanca-Settat includes the highest concentration of economic activities in the country. With an important port, airport, rail and road infrastructure, this region contributes to more than $60 \%$ of industrial production and more than $34 \%$ of the national gross domestic product. This economic dynamic attracts almost 7.12 million inhabitants or $20.44 \%$ of the national population, with an activity rate of $50.50 \%$ (HCP, 2019).

Consequently, this region has a low poverty rate $(0.4 \%)$ compared to the national average (1.4\%) and an annual expenditure per person of $22701 \mathrm{DH}$ far exceeding the national average of 18,226 DH. As for the region of Rabat-Salé-Kenitra, it turns out that it takes advantage of its status as the administrative capital of the kingdom. With a population of 4.58 million inhabitants or 
$13.53 \%$ of the total population, this region constitutes the second urban pole after Casablanca-Settat. It occupies first place in terms of health infrastructure (955 inhabitants per bed) and second place in terms of annual expenditure per person (21627 DH). This group also includes the Régions du Sud, which is emerging regions. They are Guelmim - Oued Noun, Laâyoune-Sakia Alhamra, and Dakhla Oued-Eddahab. The strong economic growth of these regions fills their desert character. Therefore, they enjoy the lowest rates of absolute poverty $(0.2 \%)$ and vulnerability $(2.2 \%)$ and the highest annual national expenditure per person $(23090 \mathrm{DH})$ in the country.

The second group includes the regions of Marrakech-Safi, Drâa-Tafilalet, and Béni Mellal-Khénifra. These regions are negatively correlated with the axis (F1). This explains the low level recorded by these regions with regard to our regional human development index (RHDI). Indeed, Marrakech-Safi has 4.52 million inhabitants and an area of 5.5\% of the national territory. $57 \%$ of the population lives in rural areas. This rural character of the region has a negative impact on its performance in education, health, and standard of living. For example, the region has a low number of years of study (3.9), a low school life expectancy (11.9), and a low annual expenditure (15051 DH) compared to the national average per person (18226 DH).

On the other hand, it records the highest rates of absolute poverty (3.5) and relative poverty (13.2) at the level of the kingdom. Almost the same trends are observed in the two other regions making up this group. In 2015, the HDI of Béni Mellal-Khénifra was 0.605 , and that of Drâa-Tafilalet was 0.608 .

The third group consists of a vast intermediate zone made up of regions with an average level of human development. It includes the regions of Souss-Massa, Tanger-Tétouan-Al Hoceima, Fès-Meknès, and the Oriental. In 2015, these regions recorded an HDI of $0.625,0.622,0.622$, and 0.610 respectively. In terms of annual expenditure per person, they register respectively $16627 \mathrm{DH}, 17752 \mathrm{DH}, 15630 \mathrm{DH}$, and $14858 \mathrm{DH}$ while the national average is $18226 \mathrm{DH}$. Regarding the relative poverty rate, Souss-Massa (19.6), and Tangier-Tétouan-Al Hoceima (16.9) are below the national average (19.6), at the time when the regions of Fès-Meknès (22.7) and the Oriental (26.1) are above it.

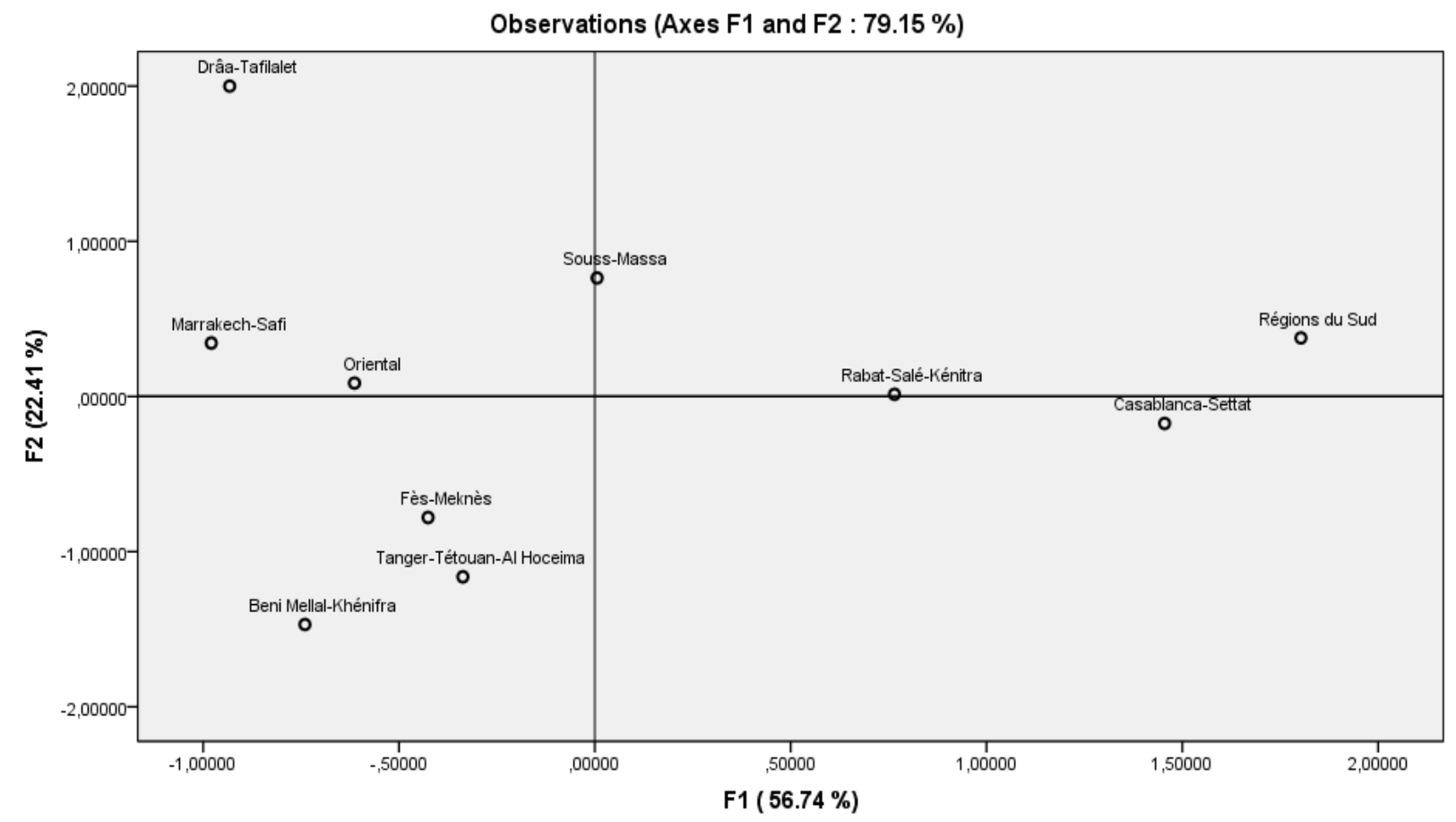

Figure 2:

Projection of the regions on the factorial plane (F1, F2)

Source: Author's computation /SPSS (Version 23.0 for Windows) Output

\subsection{Construction of a regional human development indicator (RHDI)}

The cartography elaborated by the Principal Components Analysis allowed us to draw up a typology of the Moroccan regions according to the level of human development. However, to measure the extent of regional disparities, a little later in this paper, it is useful to have a synthetic indicator covering all the areas studied, namely: education, health, standard of living, and access to basic equipment. To do this, the first factorial axis (F1) is the most relevant, since it contains $56.74 \%$ of the information, 
covers all the dimensions mentioned above and is strongly correlated with 16 of the 19 elementary indicators used in this study. Thus, to limit the effect of the scale, the coordinates of each region on this axis are reduced to the scale $[0 ; 1]$. For the $i^{\text {th }}$ region, the normalized index is in the form:

$$
\text { RHDI }=\frac{X i-\operatorname{Min}(X)}{\operatorname{Max}(X)-\operatorname{Min}(X)}
$$

With $(\mathrm{Xi})$ is the value of the variable $(\mathrm{X})$ for the region $\mathrm{i}$, Min $(\mathrm{X})$, and Max $(\mathrm{X})$ are respectively the smallest and the largest value of the variable $(\mathrm{X})$ for all the regions.

Table 2

Ranking of Moroccan regions according to the Regional Human Development Index (RHDI-2017)

\begin{tabular}{lccc}
\hline Regions & $\begin{array}{c}\text { Coordinates on } \\
\text { F1 }\end{array}$ & $\begin{array}{c}\text { Regional Index } \\
\text { of Human Development } \\
\text { (RHDI) }\end{array}$ & $\begin{array}{c}\text { Classification } \\
\text { according to the RHDI }\end{array}$ \\
\hline Régions du Sud & 1,803 & 1 & 1 \\
Casablanca-Settat & 1,455 & 0,875 & 2 \\
Rabat-Salé-Kenitra & 0,765 & 0,627 & 3 \\
Souss-Massa & 0,006 & 0,354 & 4 \\
Tanger-Tétouan-Al Hoceima & $-0,337$ & 0,231 & 5 \\
Fès-Meknès & $-0,426$ & 0,199 & 6 \\
Oriental & $-0,614$ & 0,131 & 7 \\
Beni Mellal-Khénifra & $-0,740$ & 0,086 & 8 \\
Drâa-Tafilalet & $-0,932$ & 0,017 & 9 \\
Marrakech-Safi & $-0,979$ & 0 & 10 \\
\hline
\end{tabular}

Source: Author's calculation

The regional human development index reproduces the same typology obtained from the Principal Component Analysis. The regions in the first group have an RHDI that exceeds 0.5 , thus reflecting a high level of human development. Those of the second group have an RHDI between 0.1 and 0.5 , indicating an intermediate level. Whereas the regions of the third group are far behind with an RHDI below 0.1 .

\subsection{Measuring regional disparities in human development}

The Principal Component Analysis and the regional composite index showed the existence of inequalities between the regions of Morocco in terms of human development. To measure the magnitude of these disparities, we calculate the Gini index for the synthetic human development index (RHDI). For more precision, the Gini index is also calculated for the 19 elementary selected indicators, as shown in table 3.

Table 3

Gini index calculated on elementary indicators and the regional human development indicator

\begin{tabular}{|c|c|c|}
\hline Dimensions & Elementary human development indicators & Gini index \\
\hline \multirow{6}{*}{ Education } & - $\quad$ Literacy rate of 15 to 24 year-olds & 0,016 \\
\hline & - $\quad$ The net enrollment rate for 6 to 22 years old & 0,027 \\
\hline & - $\quad$ Number of years of education & 0,093 \\
\hline & - $\quad$ School life expectancy & 0,028 \\
\hline & - $\quad$ The share of the population aged 20 and over with no level of education (uneducated) & 0,081 \\
\hline & - $\quad$ The share of the population aged 20 and over with high school level and above & 0,128 \\
\hline \multirow{3}{*}{ Health } & - $\quad$ Medical consultation rate & 0,114 \\
\hline & - The proportion of women receiving prenatal consultation during pregnancy & 0,052 \\
\hline & - The proportion of women who gave birth in a supervised environment & 0,033 \\
\hline \multirow{3}{*}{$\begin{array}{l}\text { Standard of } \\
\text { living }\end{array}$} & - $\quad$ Average annual expenditure per person in the current DH & 0,123 \\
\hline & - Vulnerability rate & 0,318 \\
\hline & - Relative poverty rate & 0,275 \\
\hline
\end{tabular}

Please cite this article as: AGUENANE, N. E. (2020). Regional Disparities In Human Development: The Case Of Moroccan Regions. International Journal of Social Sciences and Economic Review, 2(2), 28-34. https://doi.org/10.36923/ijsser.v2i2.57 


\begin{tabular}{llll}
\hline & - & Absolute poverty rate & 0,452 \\
& - & Percentage of the population with an annual expenditure below the national average & 0,113 \\
\hline & - & The proportion of households connected to the drinking water network & 0,068 \\
Access to basic & $-\quad$ The proportion of households connected to the sewer system & 0,117 \\
social amenities & $\begin{array}{l}\text { latrines } \\
\text { The proportion of rural households with access to dispensaries or communal health } \\
\end{array}$ & 0,353 \\
& centers & 0,206 \\
\hline
\end{tabular}

Regional Human Development Index (RHDI)

Source: Author's calculation

The Gini index registering a value of 0.528 shows an alarming degree of inequality between the ten regions of Morocco. We can say that the distribution of the level of human development is unequal. The greatest inequalities arise from living standard indicators such as the absolute poverty rate $(0.452)$, the vulnerability rate $(0.318)$, and the relative poverty rate $(0.275)$. While the lowest inequalities are recorded in terms of education indicators such as the literacy rate of 15 to 24 year-olds $(0.016)$, the Net enrollment rate for 6 to 22 years old (0.027), and School life expectancy (0.028). Like education, health does not seem to be a source of significant inequalities. The ten regions are very similar in indicators such as the proportion of women who gave birth in a supervised environment $(0.033)$ and the proportion of women receiving prenatal consultation during pregnancy $(0.052)$. At a time when access to basic equipment is contributing, consequently, to widening inter-regional disparities in terms of human development. Fairly high Gini coefficients justify this for indicators such as the proportion of households evacuating wastewater in septic tanks, wells or latrines (0.353), and proportion of rural households having access to dispensaries or communal health centers (0.206).

\section{DISCUSSION OF MAJOR FINDINGS}

This empirical study has sought to achieve three main objectives. First, it drew up a typological map of the different regions of Morocco according to their level of human development. Then, it tried to classify them according to a calculated regional indicator. Finally, it attempted to measure the degree of regional disparities. This section is intended to be a discussion of these three objectives.

Regarding the first objective, the study highlights that in Morocco, three strata of regions coexist. Inequalities are high, so that we note very clearly that the country is divided into two extreme strata. One of them is about to join the countries with high human development while the other is assimilated to countries with weak human growth. These two extremes are separated by a stratum, which, on the other hand, has the level of countries with average human development. The analysis of these inequalities in the light of the 19 elementary selected indicators shows that the least prosperous regions are those which are poorly served in education, health, and especially in income.

The second objective was to classify the 10 regions according to their level of human development. To do this, a regional composite index of human development is constructed. This index (RHDI) is broader than the HDI since it aggregates 16 indicators from the four dimensions of human development; to name education, health, the standard of living, and access to basic equipment. It is used to have a clear overview of the situation in each region. The RHDI restores the same classification of regions as that of the HDI (Observatoire National du Développement Humain, 2018).

Regional inequalities being verified, the third objective was to measure the degree of these disparities. The calculation of a fairly strong Gini index (0.528) based on the regional synthetic human development index raises the gravity of these inequalities. The main sources of inequality, according to the Gini index calculated on the 19 fundamental indicators of the analysis, are an inequitable distribution of living standards and unbalanced access to basic equipment.

\section{CONCLUSION AND POLICY IMPLICATIONS}

At the end of this analysis, it can be said that human development in Morocco is marked by worrying inequalities. This paper reveals the fact that dimensions that are supposed to be sources of growth, such as the standard of living and access to basic equipment, are, on the other hand, sources of social injustice between regions. Measures for the short, medium and long term are to be considered. These include:

- An integrated regional policy that goes beyond a simple compilation of development programs, but based both on boosting local resources and on equitable redistributive measures.

- The evaluation of public action must focus on its capacity to reduce deficits in the critical dimensions of human development mentioned above as instruments for measuring its effectiveness and efficiency.

- The assessment of public expenditure should relate to its concern for social and territorial equity.

- The complementarity between the regions cannot be achieved without opening up the isolated ones and providing them with infrastructure, facilitating the exchange of goods and human capital. 
- The promotion of rights and freedoms is likely to improve the level of transparency of information and the participation of local actors in decision-making.

- Improvement of the contribution of education to human development, which remains very weak in Morocco. It is particularly a question of fighting against the school dropout, which has a negative impact on school life expectancy.

- Expansion of the health insurance system and public health care infrastructure, particularly in the least well-served areas.

- It is strengthening of territorial competitiveness by defining the key success factors and by mobilizing the comparative advantages of each region.

\section{LIMITATIONS AND PERSPECTIVES}

As with any research work, this study has limitations. There are two main limitations to note. The first one emanates from the cross-sectional approach adopted by this analysis. The second relates to its descriptive nature. However, two promising lines of research are deducted directly from the limits mentioned above. In terms of time, longitudinal analyzes over a long period with five-year steps, for example — would shed more light on the dynamics of regional disparities and on the process of catching up and convergence of regions. In order to explain and measure the determinants of each dimension, the effect of each dimension on the others and the contribution of each dimension to human development, the main dimensions of human development described in the explanatory quantitative analyzes advocating the rationale of "cause and effect" must be carried out.

\section{REFERENCES}

Amadeus, I. T. (2019). Group SA, "London Gatwick Airport increases runway capacity to 55 flights per hour and estimates an additional 2 million passengers on a single runway assisted by Amadeus ACDM Portal," 2014.

Aguenane, N. E. (2019a). Assessing well-being: welfare economics, social choice theory, and theory of justice. International Review of Economics, Management and Law Research, IREMLR, 1 (1), 1-18.

Aguenane, N. E. (2019b). Economic growth, inequality and poverty: a review in the light of the capability approach. Journal d'Economie, de Management, d'Environnement et de Droit, JEMED, 2 (2), 72-85.

Bonifas, L., Escoufier, Y., Gonzalez, P. E., \& Sabatier, R. (1984). Choix de variables en analyse en composantes principales. Revue de statistique appliquée, 32(2), 5-15.

Conseil Economique Social et Environnemental (CESE). (2016). Exigences de la régionalisation avancée et défis de l'intégration des politiques sectorielles. Auto-saisine $\mathrm{n}^{\circ} 22 / 2016$. Rabat

Conseil Economique Social et Environnemental (CESE). (2019). Le Nouveau Modèle de Développement du Maroc Contribution du Conseil Economique, Social et Environnemental. Rabat.

Duby, C., \& Robin, S. (2006). Analyse en composantes principales. Institut National Agronomique, Paris-Grignon, 80.

Jolliffe, I. T., \& Cadima, J. (2016). Principal component analysis: a review and recent developments. Philosophical Transactions of the Royal Society A: Mathematical, Physical and Engineering Sciences, 374(2065). https://doi.org/10.1098/rsta.2015.0202

Observatoire National du Développement Humain, (2018). Rapport sur le Développement Humain au Maroc 2017, Inégalités et développement Humain: contribution pour le débat sur le modèle de développement au Maroc, Synthèse. Rabat.

Observatoire National du Développement Humain, (2019). Rapport sur les Indicateurs de Suivi du Développement Humain : Niveau \& Tendances à l'échelle nationale et régionale 2012-2017. Rabat

Tamsamani, Y., Brunet-Jailly, J., Komat, A. , \& Mourji, F. (2019). Pour un modèle alternatif de développement du Maroc. Université Hassan II. Casablanca. 